\title{
PEMBANGUNAN APLIKASI PENDATAAN RUMAH SEHAT TERINTEGRASI BERBASIS WEB
}

\section{Development A Web-Based integrated Healthy Home Data Collection Application}

\author{
Yohanes Puguh Suharjito ${ }^{1)}$ Nina Setiyawati ${ }^{2)}$ \\ 1,2)Program Studi Teknik Informatika, Universitas Kristen Satya Wacana, Salatiga \\ Diterima 11 Januari 2019 / Disetujui 21 Februari 2019
}

\begin{abstract}
A house is a physical structure consisting of a room, a yard and the surrounding area that is used as a place to live and a family building facility where people spend their 70\% time. Construction of houses and environments that do not meet the health requirements can cause people to be had several health risks and also a transformation of various types diseases, especially environmental-based diseases such as dengue hemorrhagic fever, malaria, avian influenza, pulmonary tuberculosis and others. The healthy house data collection was carried out by the Community Health Center and reported it to the Primary Healthcare Office. The problems that faced by the Primary Healthcare Office in Salatiga is there is no integrated system between Community Health Center and Primary Healthcare Office in managing healthy home data. It cause in inefficient data reporting process from the Community Health Center as well as archiving healthy home data both in the Community Health Center and in the Environmental Health Sector in the Primary Healthcare Office. In this research, a Healthy Home Data Collection Application was built between the Community Health Center and the Primary Healthcare Office. The application is built using the PHP programming language, jQuery, and the CSS Bootstrap framework that helps and simplifies the reporting process as well as managing healthy home data.
\end{abstract}

Keywords: Healthy home, Data collection, Integrated, Web

\begin{abstract}
ABSTRAK
Rumah adalah struktur fisik terdiri dari ruangan, halaman dan area sekitarnya yang dipakai sebagai tempat tinggal dan sarana pembinaan keluarga dimana $70 \%$ waktu seseorang dihabiskan. Konstruksi rumah dan lingkungan yang tidak memenuhi syarat kesehatan dapat menyebabkan orang terkena beberapa risiko kesehatan dan juga menjadi faktor risiko penularan berbagai jenis penyakit khususnnya penyakit berbasis lingkungan seperti Demam Berdarah Dengue, Malaria, Flu Burung, TB Paru dan lain-lain. Pendataan rumah sehat tersebut dilakukan oleh Puskesmas dan melaporkannya ke Bidang Penyehatan Lingkungan Dinas Kesehatan Kota (DKK). Kendala yang dihadapi Bidang Penyehatan Lingkungan DKK Salatiga adalah belum adanya sistem yang terintegrasi antara Puskesmas dan Bidang Penyehatan Lingkungan DKK dalam mengelola data rumah sehat. Hal ini menyebabkan tidak efisiennya proses pelaporan data dari Puskesmas juga pengarsipan data rumah sehat baik di Puskesmas amupun di Bidang Penyehatan Lingkungan DKK. Pada penelitian ini dibangun Aplikasi Pendataan Rumah Sehat yang terintegrasi antara Puskesmas dengan Bidang Penyehatan Lingkungan DKK. Aplikasi dibangun menggunakan bahasa pemrograman PHP, jQuery, dan framework CSS Bootstrap yang membantu dan mempermudah proses pelaporan serta pengelolaan data rumah sehat baik di Puskesmas maupun di Bidang Penyehatan Lingkungan DKK.
\end{abstract}

Kata Kunci: Rumah Sehat, Pendataan, Terintegrasi, Web

\footnotetext{
*Korespondensi Penulis:

E-mail: nina.setiyawati@staff.uksw.edu
} 


\section{PENDAHULUAN}

Rumah adalah struktur fisik terdiri dari ruangan, halaman dan area sekitarnya yang dipakai sebagai tempat tinggal dan sarana pembinaan keluarga (UU No 4 Tahun, 1992). Selain sebagai salah satu komponen kebutuhan pokok manusia, rumah juga merupakan tempat dimana masyarakat menghabiskan 70\% waktunya (Baker, 2007). Akan tetapi, konstruksi rumah dan lingkungan yang tidak memenuhi syarat kesehatan dapat menyebabkan orang terkena beberapa risiko kesehatan (WHO, 2018) dan juga menjadi faktor risiko penularan berbagai jenis penyakit khususnnya penyakit berbasis lingkungan seperti Demam Berdarah Dengue, Malaria, Flu Burung, TB Paru dan lain-lain (Kepmenkes RI No 829 Tahun 1999).

Melihat hal tersebut, Departemen Kesehatan Republik Indonesia memberikan prinsip standar rumah sehat (Depkes RI, 2002) yang melandaskan pada Keputusan Menteri Kesehatan No.829/Menkes/SK/VII/1999 tentang Persyaratan Kesehatan Perumahan. Hal ini diperlukan untuk memastikan bahwa setiap tempat tinggal layak dari segi kesehatan.

Salatiga adalah salah satu kota di provinsi Jawa Tengah yang memiliki jumlah kepala keluarga 755,529 (BPS, 2018) dan jumlah rumah sebanyak 41,592 dengan jumlah rumah sehat di Salatiga adalah 87,45\% (Dinas Kesehatan Jawa Tengah, 2017). Pendataan rumah sehat tersebut dilakukan oleh Puskesmas di setiap wilayah kerja masing-masing Puskesmas dan melaporkannya ke Bidang Penyehatan Lingkungan Dinas Kesehatan Kota (DKK) salah satu tugasnya adalah mengawasi dan memastikan perkembangan jumlah rumah sehat di Salatiga.

Kendala yang dihadapi Bidang Penyehatan Lingkungan DKK Salatiga adalah belum adanya sistem yang terintegrasi antara Puskesmas dan Bidang Penyehatan Lingkungan DKK dalam mengelola data rumah sehat. Hal ini menyebabkan tidak efisiennya proses pelaporan data dari Puskesmas juga pengarsipan data rumah sehat baik di Puskesmas amupun di Bidang Penyehatan Lingkungan DKK.

Pada penelitian ini dibangun Aplikasi Pendataan Rumah Sehat yang terintegrasi antara Puskesmas dengan Bidang Penyehatan Lingkungan DKK. Aplikasi dibangun menggunakan bahasa pemrograman PHP, jQuery, dan framework CSS Bootstrap.

\section{METODE PENELITIAN}

Penelitian dilakukan dengan menggunakan metode prototyping. Tahapan pada metode ini terdiri dari tiga tahapan yaitu: 1) listen to customer. 2) build mock up. 3) customer test drive. Seperti terlihat pada Gambar 1.

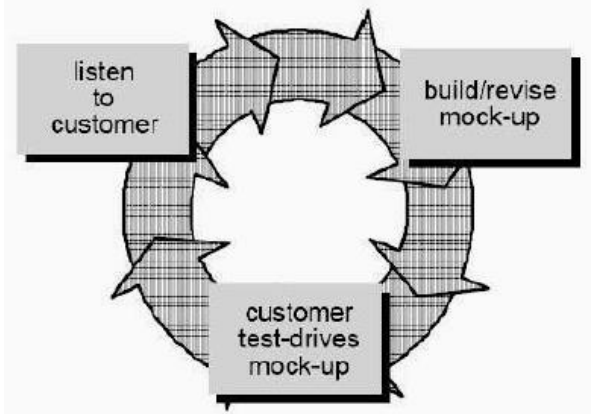

Gambar 1 Tahapan Metode Prototyping (Hasibuan, 2007)

Metode Prototyping dilakukan secara bertahap dimulai dari mengembangkan suatu prototipe yang merupakan bentuk dasar dari system (Hasibuan, 2007), untuk kemudian dapat dikembangkan atau disempurnakan lagi.

Adapun tahap-tahap yang dilakukan dalam Prototyping Model sebagai berikut:

\section{Listen to customer}

Pada tahap ini dilakukan pengumpulan data dan pengumpulan kebutuhan aplikasi dengan metode wawancara kepada Kepala Bidang Penyehatan Lingkungan yang menangani dan mengetahui proses pelaporan rumah sehat. Adapun kebutuhan aplikasi adalah fitur pendataan rumah sehat dari Puskesmas, melihat laporan rekapitulasi data oleh administrator. 
2. Build/revise mook-up

Pada tahap ini dilakukan pembangunan prototipe dengan membuat rancangan aplikasi. Untuk mengetahui hubungan antara user dengan aplikasi maka dirancanglah use case diagram. Use case

diagram adalah diagram yang mendeskripsikan interaksi satu atau lebih aktor dalam pemakaian sistem dan peran aktor dalam menggunakan fungsi-fungsi sistem. Use Case Diagram sistem yang akan dibangun ditunjukkan pada Gambar 2.

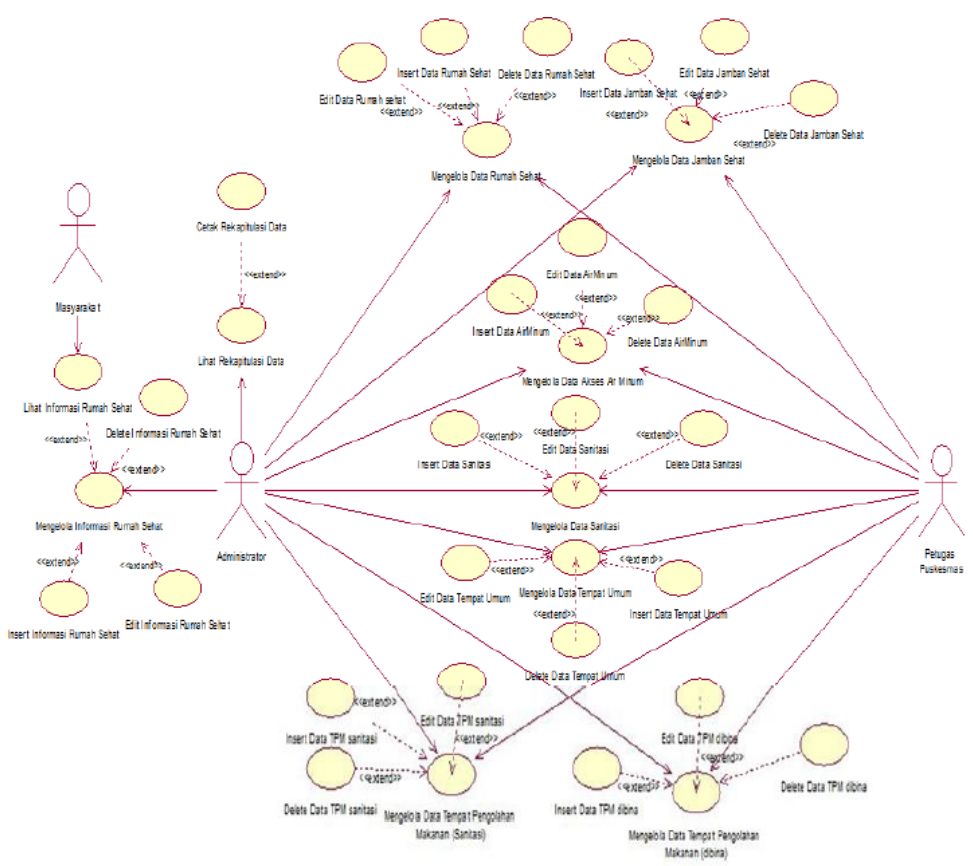

Gambar 3 Use Case Diagram Aplikasi Pendataan Rumah Sehat

Dari Gambar 2 terlihat bahwa aplikasi yang dibangun mempunyai 3 pengguna yaitu masyarakat, petugas Puskesmas dan administrator dari DKK Salatiga. Masyarakat dapat melihat informasi mengenai Rumah Sehat dan Lingkungan Sehat, serta syarat-syarat untuk menjadi Rumah Sehat dan Lingkungan Sehat. Petugas Puskesmas mempunyai hak akses untuk membantu administrator dalam memasukkan, mengubah dan menghapus data Rumah Sehat dan Lingkungan Sehat. Administrator mempunyai hak akses yang lebih tinggi dari pada masyarakat dan petugas Puskesmas, yaitu dapat mengelola data-data yang ada di aplikasi dan melihat serta mencetak hasil rekapitulasi.

Perancangan lain yang dilakukan adalah merancang basis data. Adapun relasi basis data Aplikasi Pendataan Rumah Sehat terlihat pada Gambar 3.

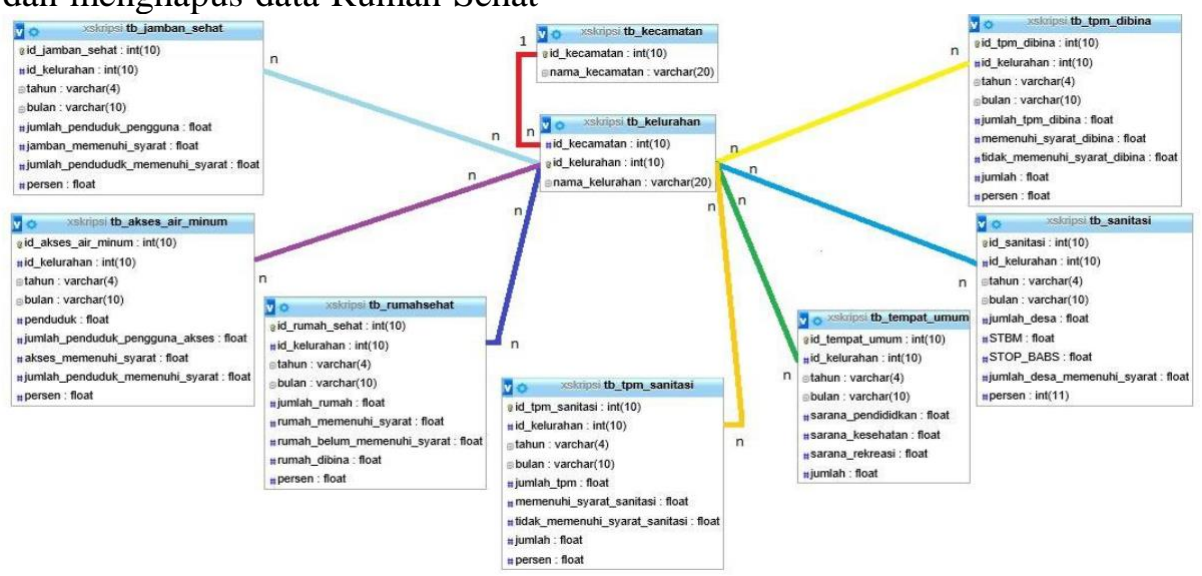

Gambar 3 Relasi Basis Data Aplikasi Pendataan Rumah Sehat 
Arsitektur aplikasi yang dibangun terlihat pada Gambar 4.

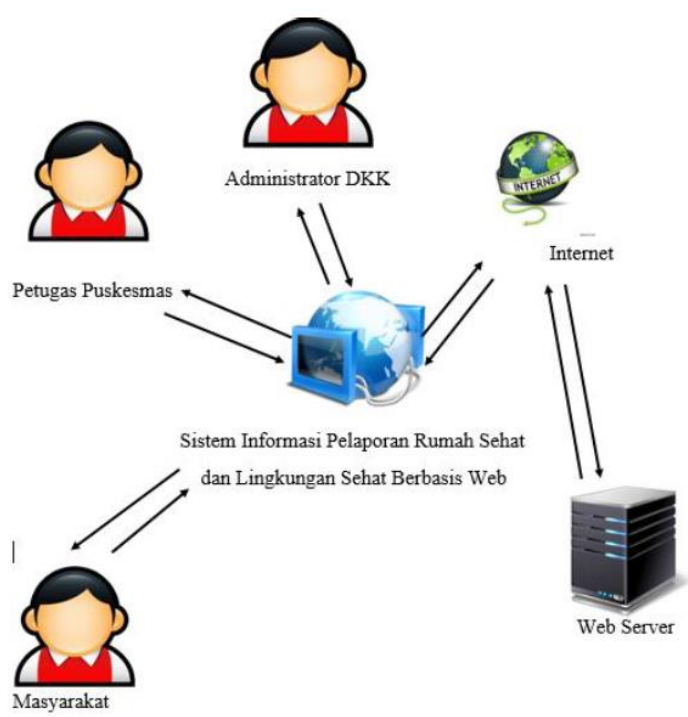

Gambar 4 Arsitektur Aplikasi Pendataan Rumah Sehat

Gambar 4 menunjukkan arsitektur Aplikasi Pendataan Rumah Sehat. Arsitektur aplikasi merupakan struktur terkait dengan pemetaan komponen-komponen fisik aplikasi. Hal ini termasuk lokasi komponenkomponen dalam jaringan (Utomo, 2014).

\section{Customer test drives mook-up}

Pada tahap ini dilakukan pengujian prototipe yang telah dibangun, jika ditemukan kekurangan, maka akan dilakukan lagi tahap pertama metode Prototyping. Pengujian aplikasi dilakukan langsung oleh Kepala

Bidang Penyehatan Lingkungan dan petugas Puskesmas dan dinyatakan sesuai dengan kebutuhan, sehingga akan dilanjutkan ke pengembangan aplikasi dengan menggunakan bahasa pemrograman PHP, jQuery, dan framework CSS Bootstrap.

\section{HASIL DAN PEMBAHASAN}

Hasil dari penelitian ini adalah Aplikasi Pendataan Rumah Sehat, dimana aplikasi ini mempunyai tiga pengguna yaitu petugas Puskesmas, pegawai DKK sebagai administrator dan masyarakat. Satu administrator dari DKK dan enam Puskesmas diantaranya Puskesmas Kalicacing, Puskesmas Cebongan, Puskesmas Mangunsari, Puskesmas Sidorejo Kidul, Puskesmas Sidorejo Lor dan Puskesmas Tegalrejo. Petugas Puskesmas memiliki tugas untuk membantu administrator dalam melakukan pencatatan data rumah sehat, dalam hal ini Puskesmas hanya dapat memasukkan data rumah sehat yang diperoleh sesuai wilayah kerja masingmasing Puskesmas dan hanya dapat melihat data rumah sehat sesuai wilayah kerja Puskesmas. Adminsitrator DKK memiliki hak akses untuk mengelola data rumah sehat, membuat rekapitulasi dan melihat semua data yang telah dimasukkan oleh semua Puskesmas di Salatiga.

Di modul Puskesmas, petugas Puskesmas dapat memasukkan data rumah sehat dan beberapa data lainnya seperti akses air minum dan jamban sehat, serta data desa sanitasi, tempat umum memenuhi syarat, Tempat Pengelolaan Makanan (TPM) sanitasi, dan TPM dibina dan uji petik. Gambar 5 menunjukkan halaman untuk memasukkan data rumah sehat dan Gambar 6 menunjukkan data rumah sehat di wilayah kerja Puskesmas Kalicacing.

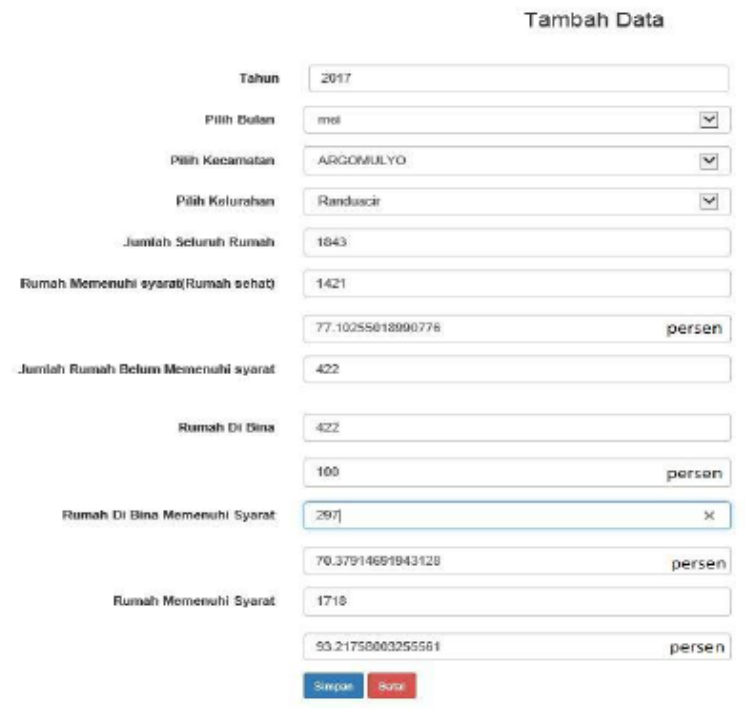

Gambar 5 Halaman Memasukkan Data Rumah Sehat 


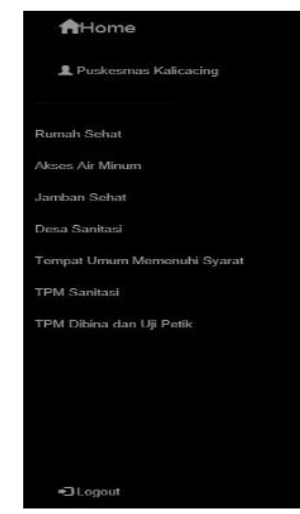

Data Presentasi Rumah Sehat Menurut Kecamatan dan Puskesmas

rambantom

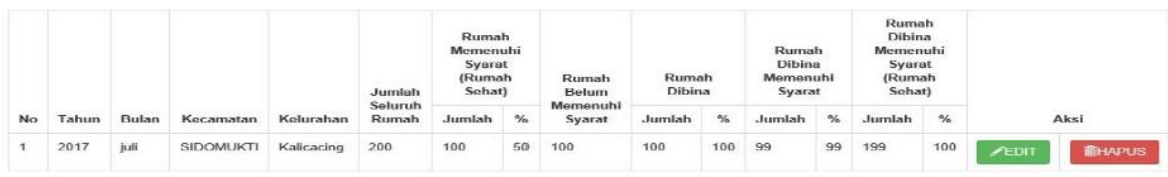

Gambar 6 Data Rumah Sehat Wilayah Kerja Puskesmas Kalicacing

Di modul administrator, dapat dilihat data rumah sehat dan data aspek lingkungan sehat yang dimasukkan oleh semua
Puskesmas di Salatiga. Gambar 7 menunjukkan data akses air minum berkualitas.

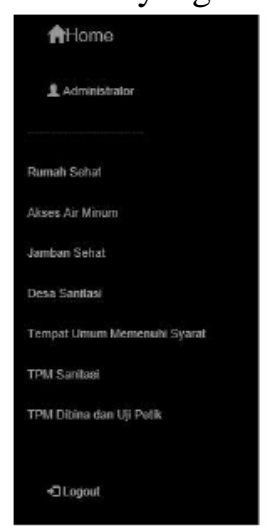

Penduduk Dengan Akses Air Minum Berkualitas(Layak)

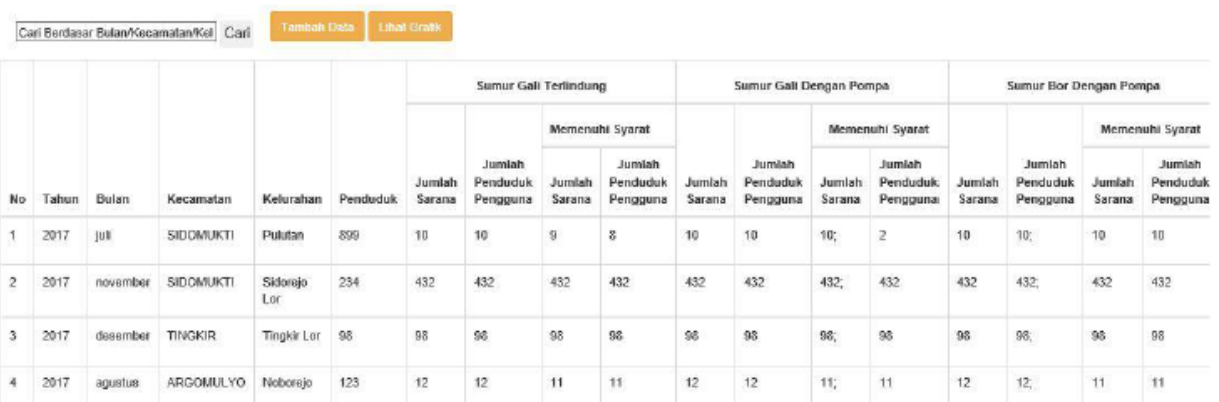

Gambar 7 Data Akses Air Minum Berkualitas

Setelah pembangunan Aplikasi Pendataan Rumah Sehat selesai, calon pengguna melakukan pengujian terhadap aplikasi untuk melihat apakah aplikasi yang dibangun sudah sesuai dengan kebutuhan yang diberikan di awal. Calon pengguna adalah pegawai Puskesmas yang bertugas dalam pendataan rumah sehat dan beberapa pegawai DKK. Terdapat 15 pegawai Puskesmas yang menjadi responden. Hasil pengujian terekam dalam kuisioner dengan penskalaan Likert. Skala Likert mengukur perilaku individu dengan merespon 5 titik pilihan pada setiap butir pertanyaan atau pernyataan: sangat setuju, setuju, netral, tidak setuju, dan sangat tidak setuju (Likert, 1932). Hasil uji pengguna terlihat pada Tabel 1.

Tabel 1 Hasil Uji Pengguna

\begin{tabular}{|c|c|c|c|c|}
\hline Pernyataan & STS & $\mathbf{N}$ & $\mathbf{S}$ & SS \\
\hline $\begin{array}{l}\text { Tampilan aplikasi sudah baik (warna background tidak } \\
\text { mencolok, tulisan terlihat, gambar jelas,) }\end{array}$ & & & 3 & 12 \\
\hline Form memasukkan data dapat digunakan dengan mudah & & 3 & 2 & 10 \\
\hline $\begin{array}{l}\text { Aplikasi mempermudah pihak Puskesmas dalam pengelolaan } \\
\text { data rumah sehat }\end{array}$ & & 5 & 7 & 3 \\
\hline $\begin{array}{l}\text { Aplikasi mempermudah pengawasan perkembangan rumah sehat } \\
\text { di kelurahan-kelurahan wilayah kerja Puskesmas di Salatiga }\end{array}$ & & 4 & 1 & 10 \\
\hline Informasi presentase rumah sehat dapat dipahami & 2 & 3 & 7 & 3 \\
\hline
\end{tabular}


Tabel 1 adalah hasil kuesioner yang diberikan kepada 15 pegawai Puskesmas. Hasil perhitungan dari kuisioner di atas terlihat di Tabel 2.

\begin{tabular}{cl}
\hline Pernyataan & Hasil Olah Skala Likert \\
\hline $\mathbf{1}$ & $96 \%$ \\
\hline $\mathbf{2}$ & $89.34 \%$ \\
\hline $\mathbf{3}$ & $77.34 \%$ \\
\hline $\mathbf{4}$ & $88 \%$ \\
\hline $\mathbf{5}$ & $74.67 \%$ \\
\hline
\end{tabular}

Dari hasil pengolahan kuesioner menggunakan skala Likert di atas, didapatkan bahwa pegawai Puskesmas menyatakan sangat setuju bahwa Aplikasi Pendataan Rumah Sehat mempermudah pengawasan perkembangan rumah sehat di kelurahankelurahan wilayah kerja Puskesmas di Salatiga, dan menyatakan setuju bahwa Aplikasi Pendataan Rumah Sehat mempermudah pihak Puskesmas dalam pengelolaan data rumah sehat.

Pengujian juga diberikan kepada pegawai DKK Salatiga dengan metode wawancara dan didapatkan bahwa Aplikasi Pendataan Rumah Sehat membantu DKK dalam mengawasi perkembangan rumah sehat di Salatiga dan mempermudah dalam mengelola data rumah sehat di Salatiga.

\section{KESIMPULAN}

Dari pembahasan dan pengujian yang dilakukan didaptkan bahwa Aplikasi Pendataan Rumah Sehat yang dibangun membantu Puskesmas dan DKK dalam mengawasi perkembangan rumah sehat di kelurahan-kelurahan wilayah kerja masingmasing dan mempermudah dalam mengelola data rumah sehat di Salatiga.

\section{DAFTAR PUSTAKA}

Badan Pusat Statistik Kota Salatiga. Kota Salatiga dalam Angka 2018. Salatiga: BPS Kota Salatiga.

Baker M, Keall M, Au EL, HowdenChapman P. Home is Where The Heart Is - Most of The Time. New Zealand Medical Journal. (2007); 120(1264):U2769.
Depkes RI. (2002). Pedoman Teknis Penilaian Rumah Sehat. Jakarta : Ditjen PPM dan PL.

Dinas Kesehatan Provinsi Jawa Tengah. Profil Kesehatan Provinsi Jawa Tengah Tahun 2017.

Hasibuan, Z.A., (2007). Metodologi Penelitian Pada Bidang Ilmu Komputer dan Teknologi Informasi, Konsep, Teknik, dan Aplikasi. Jakarta : Ilmu Komputer Univesitas Indonesia.

Kepmenkes RI No. 829/Menkes/SK/VII/1999 tentang Persyaratan Kesehatan Perumahan. Jakarta : Departemen Kesehatan R.I.

Likert RA. (1932). Technique for The Measurement of Attitudes. Archives of Psychology, 140 pp: 1-55.

Undang-Undang Republik Indonesia No 4 Tahun 1992 Tentang Perumahan dan Permukiman.

Utomo, Tri, dkk., (2014), Sistem Informasi Penyuluhan Posyandu Berbasis Web Mobile. Dinamika Informatika Vol 6 No 2.

World Health Organization. WHO Housing and Health Guidelines. 2018. 